\title{
Extending Affordable Reliable Broadband Internet to Educational Institutions in Edo State
}

\author{
Wilson Nwankwo \\ Department of Computer Science \& Information Technology, Wellspring University, Benin City, Nigeria
}

Email address:

wilson.nwankwo@wellspringuniveristy.edu,ng

\section{To cite this article:}

Wilson Nwankwo. Extending Affordable Reliable Broadband Internet to Educational Institutions in Edo State. Internet of Things and Cloud Computing. Vol. 6, No. 1, 2018, pp. 1-11. doi: 10.11648/j.iotcc.20180601.11

Received: January 16, 2018; Accepted: January 31, 2018; Published: February 27, 2018

\begin{abstract}
Information Communication Technologies have demonstrated potentials to transform the globe into a cohesive functional global village. This is evident in many instances such as Education, International trade, Manufacturing, Healthcare delivery, etc. where digital technologies have boosted growth, expanded opportunities, and improved service delivery. As interesting as it may sound the digital dividend, that is, the broader development benefits from using such technologies have lagged behind when considering their aggregate impact which is adjudged to fall shorts well as its unevenly distribution especially in developing countries. It is believed that for these technologies to benefit access to education, research and development regardless of location, the remaining digital divide, especially in internet access should be greatly reduced or even eliminated. This paper proposes a point to multipoint controlled internet provisioning model based on WIMAX technology particularly aimed at achieving an even distribution of reliable internet access across tertiary Institutions in Edo state of Nigeria.
\end{abstract}

Keywords: WIMAX, Edo State, Tertiary Education, ICT, Broadband, Internet

\section{Introduction}

\subsection{Geography of Edo State}

Edo State was carved out of the defunct Bendel State of Nigeria in 27 August 1991 by the military administration of General Ibrahim B. Babangida. With Benin City as capital, Edo State adjudged the seventh-largest Nigerian state with a population of approximately 4 million occupying an area of approximately 17,802 square kilometres. Edo state is home to several ethnic groups among which are: Otuo, Bini (Edo), Esan, Akoko, Igarra, Ora, Ijo and Afemai. Edo State is bounded on the north and east by Kogi State, on the west by Ondo State and on the south by Delta State. Generally, it is a low-lying area except in the north where undulating hills are common. The main towns in the state are Benin which is capital of the ancient Bini kingdom; Ubiaja; Auchi; Ekpoma; and Uromi. Administratively, the State is divided into eighteen local council areas. Figure 1 shows the map of Edo State with the eighteen (18) local government areas. Tourist attractions in Edo State include the Emotan Statue in Benin City, Ise Lake and River Niger Beach in Agenebode, EtsakoEast; Mike Akhigbe Square at fugar, Ambrose Alli Square, Ekpoma, River Niger Beaches at Ilushi, BFFM Building at
Ewu, College of Agriculture and Aqua Culture Technology, Agenebode, Okpekpe with its hills and scenes and the Usomege Hills at Apana-Uzairue, Somorika hills in Akoko Edo, where a government-run tourist center at Ososo is set among spectacular scenery. Edo State is endowed with abundant natural resources such as: crude oil, natural gas, clay chalk, marbles and limestone. However, Agriculture is the predominant occupation of people of the State with the major cash crops being rubber, cocoa and palm produce. Other agricultural produce are yams, cassava; rice, plantains, guinea-corn, and assorted types of fruits and vegetables. Industries in the State include Bendel Cement Company, Okpella, Bendel Brewery, Benin City, Bendel Pharmaceutical PLC, Benin City, and Bendel Feed and Flour Mills, Ewu. Other small-scale industries abound. Prominent institutions of higher learning in the State including public and private are: Ambrose Alli University Ekpoma, Edo University Iyamho, University of Benin, Benson Idahosa university Benin, Samuel Adegboyega University Ogwa, Wellspring University, Igbinedion University Okada, Tayo Akapata University of Education Ekiadolor, Federal Polytechnic Auchi, Lighthouse Polytechnic Evbuonosa, Edo State Polytechnic Usen, Shaka Polytechnic Benin city, Edo State College of Agriculture Iguoriakh, etc. 


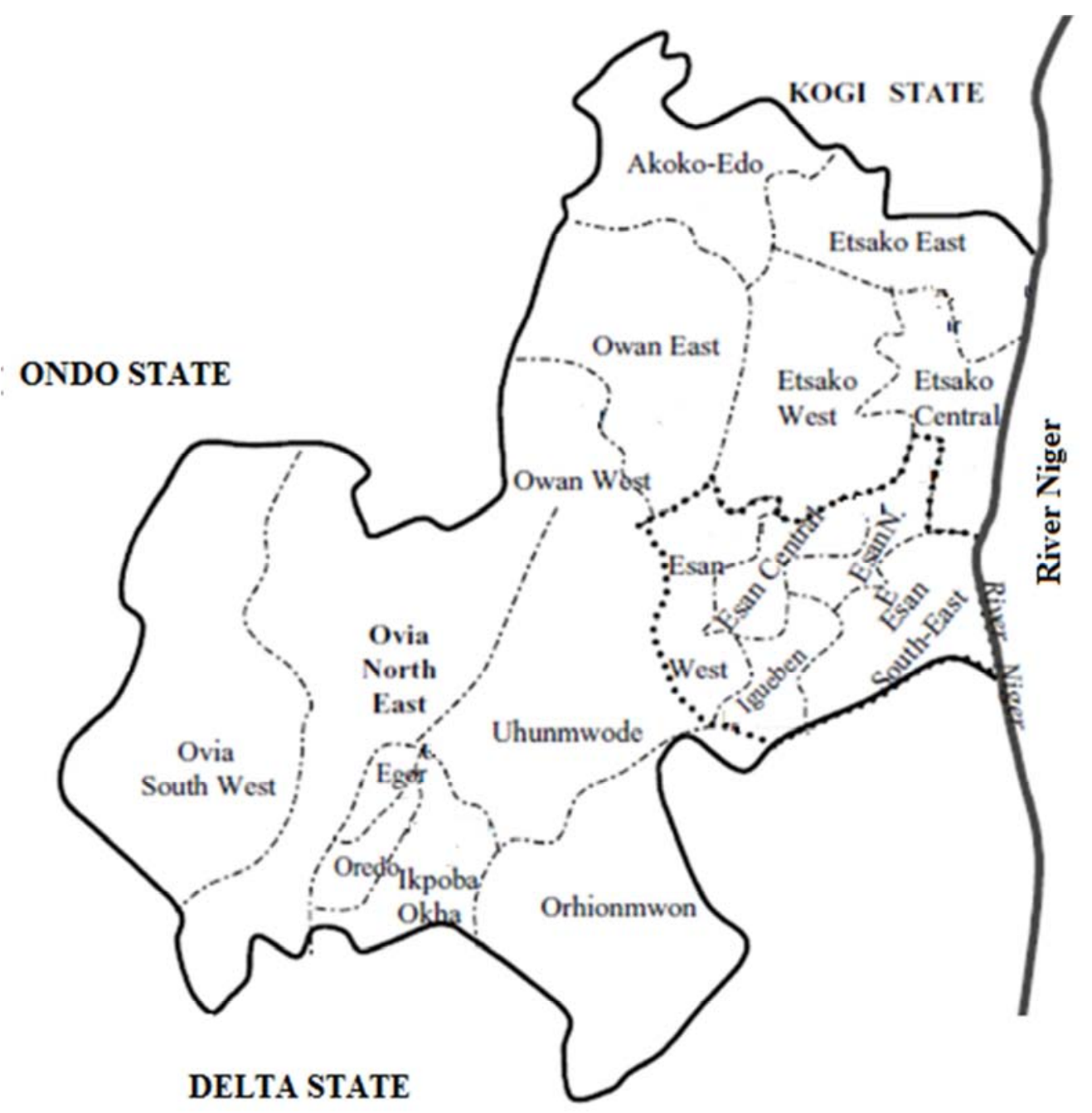

Figure 1. Map of Edo State of Nigeria showing it 18 local councils.

\subsection{Problem Definition}

Information Communication Technologies have demonstrated its potential to transform the globe into a cohesive global village. This is evident in many instances such as Education, International trade, Manufacturing, Healthcare delivery, etc. where digital technologies have boosted growth, expanded opportunities, and improved service delivery. According to the International Telecommunication Union, "In the 21 st century, the social and economic development of every country on earth will depend on Broadband networks". The statement is widely corroborated in most quarters owing to the influence of internet technologies on every sector of the human endeavour.

Nigeria is rated as one of the dominant markets for telecoms investment in Africa with about 140 million mobile subscribers as of September 2017 [1] other big markets being Egypt and South Africa respectively. The International Telecommunications Union [2] puts Nigeria's mobile broadband subscription at 21.8 per cent, a rate that is negligible compared to needs across all spheres. According to the Nigerian Communications Commission report, Nigeria is rated as one of the most important mobile subscription and Internet markets in the world with about 93.9 million people having access to Internet connection and Internet penetration of 47.33 per cent whereas broadband penetration according to the NCC is adjudged at a contestable penetration rate of $21 \%[1]$.

As interesting as it may sound the digital dividend, that is, the broader development benefits from using such technologies have lagged behind when considering their aggregate impact which is adjudged to fall short as well as its unevenly distribution. It is believed that for these technologies to benefit the educational sector regardless of the location of the Institution, useful, reliable and affordable internet access should be extended to all educational institutions especially the tertiary institutions.

\subsection{Aim and Objectives}

This study is aimed at discussing the various internet challenges in Edo State and the way forward in attaining an affordable and reliable solution for use by Educational Institutions in Edo State of Nigeria. The objective of this study is to identify and implement a reliable internet solution 
that would support economic growth and productivity through research and learning, as well as improving global community integration in locations in Edo State and its hinterlands especially where tertiary educational institutions are located.

\section{Review of Relevant Internet Technologies}

As in most climes, Internet connectivity can be achieved via two main technologies i.e. narrowband and broadband [3] connections. Technologies using the narrowband e.g. dial-up links provide a slow connectivity which is not suitable for modern applications. In recent years, it is interesting to note that Nigeria in its effort to reduce the digital divide has witnessed a cellular revolution with a significant penetration of cellular networks in rural areas. Wireless broadband networks based on GPRS [4], WiMax [5] [6] and CDMA [7] technologies are also common though internet access through all the channels is limited due to exorbitantly high usage costs.

\subsection{Dial-up Connections}

The dial-up connection is the earliest and commonest kind of connection. Dial-up allows a computer to dial a telephone number using a public switched telephone network to connect to a Server at the Internet Service Provider's location. The existence of telephone services especial GSM service in most areas makes dial-up connections the commonest mode of connecting users to the internet.

\subsection{Broadband Connections}

Broadband connections unlike their narrowband counterpart are relatively high speed connections that may or may not need the public telephone network for its deployment. Nigeria currently has access to four undersea cables along the West Coast of Africa - GLO-1 (owned by Globacom), MainOne, South Atlantic Telecommunications Cable number 3 (SAT-3), West African Submarine Cable (WASC)/South Africa Far East (SAFE)- providing more than 19Tbps of combined broadband capacity [8].

The SAT-3/WASC, with cable length of about $14,350 \mathrm{~km}$, was deployed in 2002 jointly by NATCOM and the Federal Government. SAT-3 is a submarine fiber optic communications cable funded and owned by NatCom Development \& Investment Limited trading as NTEL and 47 other leading telecoms operators across the globe [9]. It was launched to bridge the digital divide between Africa and the developed countries; offering faster and more affordable communications channels necessary for rapid growth and development within the region. Together with WASC (West African Submarine Cable) and SAFE (South Africa Far East), SAT-3 constitutes a ground-breaking undersea cable system that connects West Africa to Europe, South Africa and Asia. This SAT-3/WASC/SAFE cable system is divided into two subsystems - the 'SAT-3/WASC' in the Atlantic
Ocean and 'SAFE' in the Indian Ocean. It is the longest cable system in the world (about 22, 800km). in addition, NTEL offers capacity and dark-fibre on its network of $1,100 \mathrm{~km}$ metro-fibre ducts across six major cities and $4,000 \mathrm{~km}$ of inter-city fibre rights-of-way [9].

Main One cable trading as Main One [10] offers a fibre optic cable length of 7,000 km, and commenced operations in 2010. Globacom in a similar vein invested $\$ 800 \mathrm{~m}$ in its 9,800km Glo 1 cable. The West African Submarine Cable, with cable length of $14,530 \mathrm{~km}$ is largely by the MTN Group, was deployed in 2012 and upgraded in 2015. African to Europe submarine cable also serves Nigeria and 17 other African countries.

In addition to mainstream fibre broadband providers, there are also many consumer-oriented providers scattered across the country with more spread in the Lagos axis; and some of which employ a combination of Satellite and Microwave in providing Internet services to end users. Like the dial-up, the choice of a broadband link is dependent on certain prevailing factors such as: location of the user, type of package, the cost of subscription and availability of service. For instance internet users at many remote and rural areas may not have access to fibre connections as such facilities may not exist there. Broadband connections may be classified into: Fixed broadband and Wireless broadband.

\subsubsection{Fixed Broadband}

Fixed broadband technologies that can offer downstream speed above 256kbps include: Digital subscriber line (DSL), Cable modem, Fibre connection Broadband over power lines (BPL). These technologies are briefly discussed below.

\section{a. Digital Subscriber Line (DSL)}

DSL uses the traditional copper telephone lines installed by public switched telephone network operator across offices and homes to provide a faster internet access at a speed much higher than the dial-up. Distance from a location to a telephone exchange and the capacity/quality of the copper phone line are factors that limit the speed and availability of a DSL connection. Two most widely used variants of DSL are:

i. Asymmetrical Digital Subscriber Line (ADSL) exhibits a faster downlink speeds than its uplink using the same phone line that provides voice call service.

ii. Symmetrical Digital Subscriber Line (SDSL) unlike ADSL maintains same good bandwidth in both uplink and downlink without any allowance for voice phone usage and usually ideal for businesses/users that engage in exchange of multimedia data such as video conferencing, backup services, etc.

\section{b. Cable modem}

Cable connections unlike DSL are not limited by distance. Their signal strengths don't weaken over long distances. However, Cable internet providers are not popular in this part of Nigeria.

c. Fibre Broadband 
Fibre broadband offers very high speed connectivity of up to $330 \mathrm{Mbps}$ with optical fibre using light to transmit/receive data with less susceptibility to interference, higher bandwidth, longer distance, absence of electromagnetic radiation leak from the cable unlike in DSL connections. Existing implementations include: Fibre to the cabinet (FTTC), Fibre to the building (FTTB), Fibre to the home/premises (FTTH/FTTP), and Broadband Over Power line (which apparently does not exist in Nigeria).

In FTTC, the optic fibre runs from an exchange to a street cabinet that houses Broadband equipment from where a supply is made to buildings and homes via the provider's existing network. Figure 2 shows a FTTC configuration. The FTTB provides optic fibre connection from the exchange to a point in a shared building from where other cabling connects to offices or flats. Fibre to the home/premises (FTTH/FTTP) as illustrated in the diagram in Figure 3, offers an end-to-end full fibre connection from the service provider's exchange or point of presence (POP) to the subscriber's home or office with downstream speeds of about $330 \mathrm{Mbps}$ or more and an upstream of $30 \mathrm{Mbps}$ and beyond.

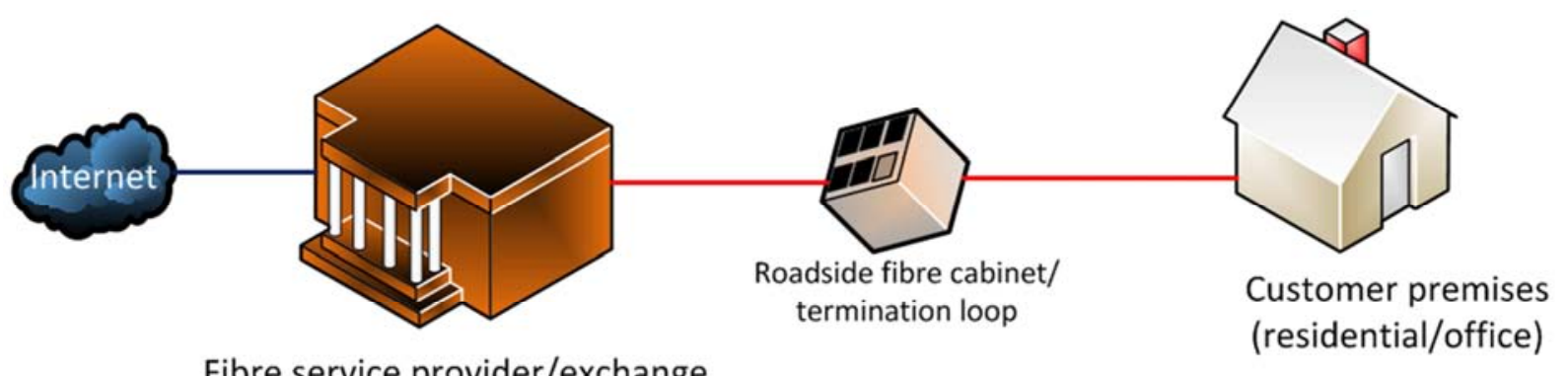

Fibre service provider/exchange

Figure 2. Fibre to the cabinet.

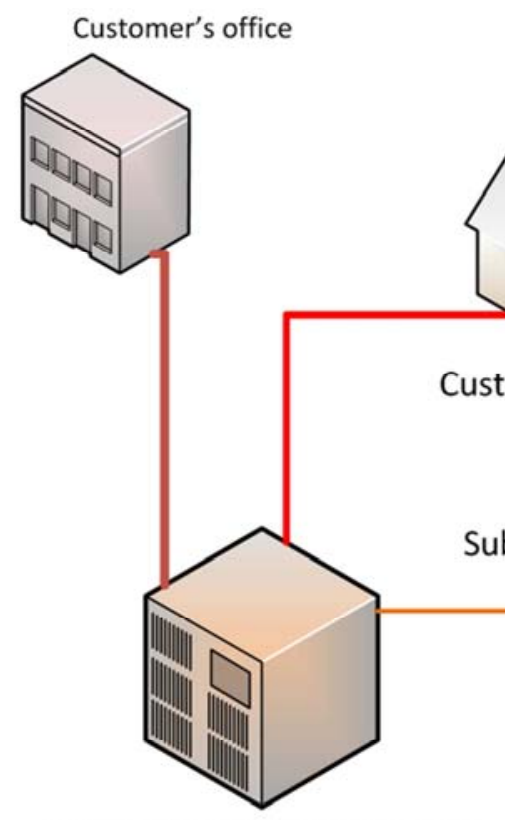

Fibre point of presence(local loop)

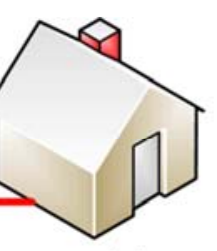

ustomer's house

Submarine cable(e.g. MainOne cable, SAT-3/WASC,etc)

Indefeasible right of use

Fibre point of presence(remote loop)

Figure 3. Fibre to the premises/house.

In Nigeria, there is significant fibre optic network distribution covering a distance of $37,104 \mathrm{~km}$ spread across the Northern and Southern regions as represented in the map in Figure 4 by thick dark-green legends, however, actual fibre deployments for useful purposes across the country is still in the infancy stage as majority of the states are not yet covered presently. According to the National Broadband Plans, "a review of the Fibre cable infrastructure map indicates that Nigeria already has a substantial amount of national backbone infrastructure installed by multifarious licensed carriers; even though it can be observed that the infrastructure is seen to be concentrated only on certain routes connecting state capitals and big urban cities. While some routes have multiple cables installed, vast expanses of rural areas are left out. For instance, there are about six fibre optic networks between Lagos and Abuja alone; while other routes in the country have none".

In the map, the legend in green shows the existing fibre optic network distribution routes whereas the red legend shows the currently planned fibre distribution. 


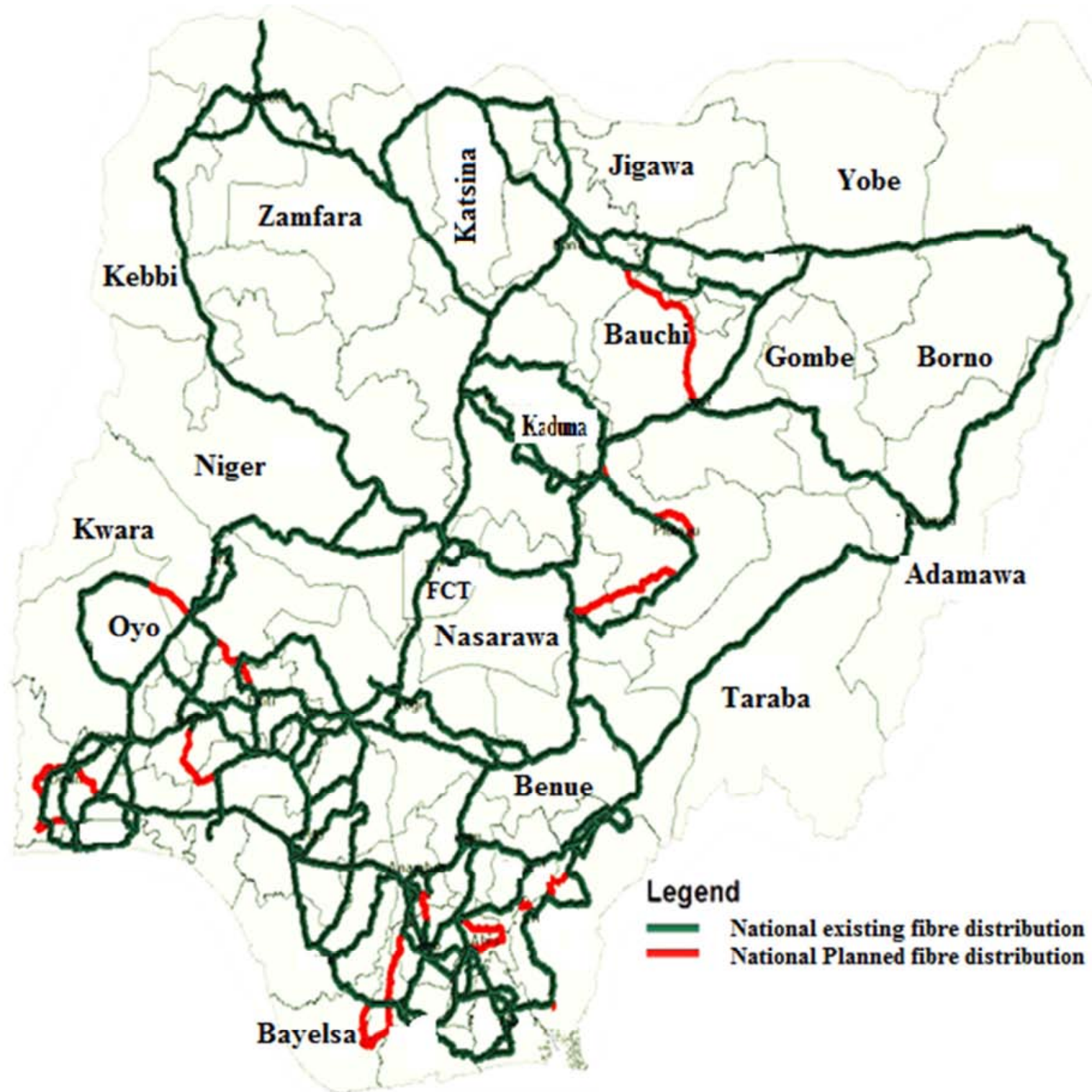

Figure 4. National Fibre Optic Map [Source: Universal Service Provision Fund].

\subsubsection{Wireless Broadband}

Wireless broadband technology employs microwave radios in distribution from provider to internet user. They are usually a good option in remote and sparsely populated areas where DSL or Cable modem service would be costly to provide. Two variants are used across Edo state: Mobile broadband and Fixed wireless broadband. The Mobile broadband service can offer speeds of at least $256 \mathrm{kbps}$ via mobile phones, laptops, PDAs, etc. In Nigeria, technologies built to operate on $4 \mathrm{G}$ standards such as long term evolution (LTE) and WIMAX (Worldwide Interoperability for Microwave Access) are not uncommon. Fixed wireless broadband uses fixed wireless communication links such as Microwave radios which often require a clear line of sight between the transmitter and receiver equipment. ISPs offer these services using licensed and unlicensed devices. It has gained much acceptance over the years because of its ease of deployment, advanced technology, long distance of coverage and pricing.

Microwave connections (WiFi \& WiMAX) provide reliable point-to-point and point-to-multipoint connectivity using radio signals in licensed and unlicensed frequencies. The radios are deployed on transmission towers/masts (ground stations) of appropriate height to link transceiver equipment located at the top of client's building or tower. They can span tens of kilometres and are scalable with base stations without significant loss of signals with throughput from $20 \mathrm{Mbps}$ to 1 Gbps thus can support video on demand (VOD), IPTV and VOIP services. They are relatively cost effective with low maintenance cost and easy to set up provided there is a line-ofsight between the two locations to be connected. In recent times, an adaptive antenna also called smart antenna is either built-in or supplied as part of Microwave transmitters/receivers. These antennas use multipleinput/multiple-output (MIMO) techniques with orthogonal 
frequency modulation (OFDM) at both transmitter and receiver stations to resolve signal distortion issues thus ensuring gains in data throughput and link coverage.

WiMAX (IEEE 802.16 Air interface specification) is very similar to WiFi but exhibits a higher speed and longer range of coverage and scalability. A WiMAX station can connect directly to the Internet using a high-bandwidth, wired connection or to another WiMAX tower using a line-of-sight, microwave link. A single WiMAX base station can cover up to 3,000 square miles [10]. WiMAX can offer non line-ofsight service using lower frequencies (2-11ghz) and line-ofsight service using higher frequencies often covering larger area. Figure 5 shows how a WiMAX-compliant service can be used to provide high speed broadband service over a large area. In Nigeria, Wireless technology is the primary delivery medium for broadband access. The licensing, rollout and upgrade of Mobile networks based on 2.5G (GPRS), EDGE, UMTS, HSPA, HSPA+, HSUPA, HSDPA and CDMA EVDO technologies, as well as, the introduction of smartphones and other mobile devices with seamless capability to connect the internet have been responsible for the current growth in internet access and usage recorded in Nigeria [8]. It is expected that the trend will receive further boost with the wider rollout of $3 \mathrm{G} / 4 \mathrm{G}$ across the country making it possible for many subscribers to access broadband internet using their mobile devices. Currently outside the key cities of Lagos, Abuja and Port Harcourt, broadband access is generally limited.
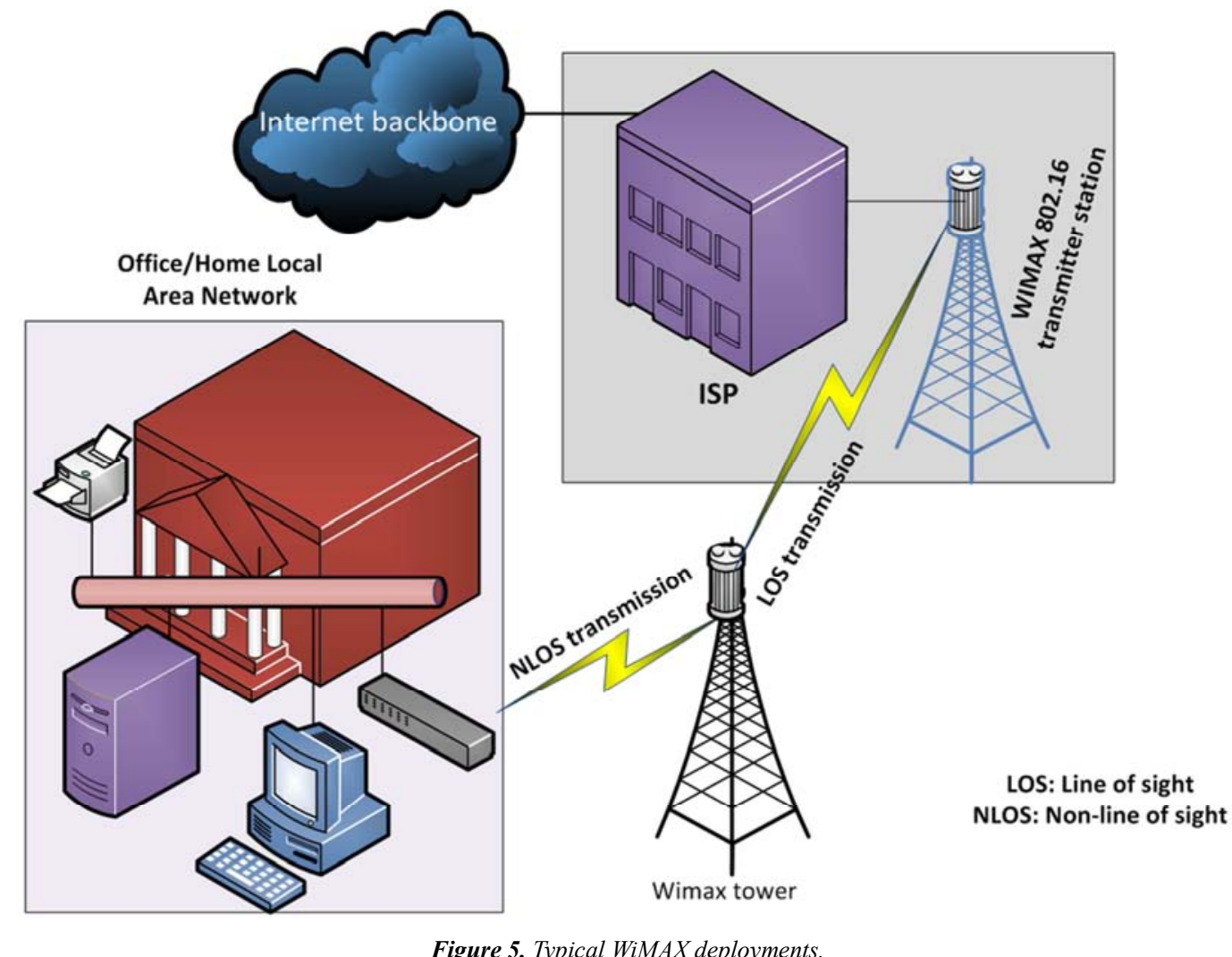

Figure 5. Typical WiMAX deployments.

\subsubsection{Satellite Broadband}

Prior to the advent of modern satellites, Satellite connections were rarely classified as broadband links owing to the high latency associated with such connections which averaged about 638 milliseconds 20 times worse than nonsatellite services [12] and the conventional context of usage of the term "broadband". For instance, in the United States, the Federal Communications Commission changed the definition of broadband in 2015 to mean an internet connection bandwidth wherein the minimum download speeds ranges from $4 \mathrm{Mbps}$ to $25 \mathrm{Mbps}$, and the minimum upload speed from $1 \mathrm{Mbps}$ to $3 \mathrm{Mbps}$ [13]. Nevertheless, the satellite provides the widest coverage irrespective of the terrain and geographical location and can be deployed without telephone infrastructure, wireless base stations or exchanges. Satellite Internet infrastructure use three basic components: a satellite in geostationary orbit (geosynchronous Earth orbit, or GEO), a number of ground stations called gateways which relay data to and from the satellite via radio waves, a VSAT (very-small-aperture terminal) dish antenna with a transceiver and a satellite modem usually located at the customer's premises. A centralized network operations center (NOC) is may be used for monitoring the satellite system. Generally, Conventional Satellite-based networks are known to exhibit high latency and signal losses due to poor weather conditions. High capacity Ka-band satellites make use of multiple narrow spot beaming technology operating at higher frequencies (26.040Ghz) thereby providing higher capacity, speed and consistent high data throughput over the conventional $\mathrm{Ku}$ and $\mathrm{C}$ band satellites. Downlink speeds of up to $30 \mathrm{Mbps}$ and 
uplink speeds of up to $6 \mathrm{Mbps}$ [14] are attainable compared to ADSL's average download speed of $3.8 \mathrm{Mbps}$ [15] in remote areas. It is also interesting to note that the newer mobile satellites such as the Immarsat Global xpress offer super-fast Ka-band broadband with downlink speeds of up to 50 Megabits per second download and up to 5 Megabits per second upload over the compact user terminals [16]. However the high capacity Ka-band unlike the $\mathrm{C}$ band is greatly hampered by extreme weather conditions. According to [17] weather effects on Ka-band high capacity satellites could be mitigated via adaptive power control, adaptive modulation and coding and gateway site planning. Satellite broadband providers in and around Edo State include Hyperia, iPNx, e-Stream, etc.

\section{Review of Broadband Market in Nigeria}

Liberalisation of telecommunication markets of the members of the World Trade Organization (WTO) of which Nigeria is a member formalised in 1998 in the Basic Telecommunication Agreement (BTA). Following the adoption of the BTA (also called the Fourth Protocol to the General Agreement on Trade in Services was adopted on 30 April 1996 and entered into force on 5 February 1998), more than 100 countries began the liberalisation process, characterised by the privatisation of national telecommunication monopolies, the introduction of competition, and the establishment of national regulators [18]. Nigeria is among the countries that have to a certain extent liberalised their telecommunication markets especially the long distance operations market.

Broadband market in Nigeria may be regarded as a dynamic one though still in its infancy owing to its predominant wireless and domination by the fixed wireless access operators. Like other telecommunications services, Broadband services are regulated by the Nigerian Communications Commission (NCC). The NCC regulates long distance operations amongst other services. Long distance implies the distance extending from one switching exchange to another, which is not located within the same city. Long distance network operators are telecommunications operators licensed to construct, own and operate transmission networks for carrying long distance telecommunications services such as voice, data and video within Nigeria.

Having liberalized the long-distance market to boost connectivity in addition to the two national carriers, Nigeria has about 8 national long-distance operators (NLDOs) that have ongoing fiber backbones in different regions of the country. The mobile operators have also deployed their own independent national fiber and microwave backbones, and the unified access license granted to the mobile operators allows allow them to commercialize these backbones. A key factor has been the entry of foreign operators into this market, through the acquisition of Nigerian operators.
According to the National Broadband Plan 2013-2018, the broadband supply chain comprises of international connectivity, a national backbone network, metropolitan access links, and the local access network (the last mile)[8]. Nigeria is home to a number of submarine cables which provides over 11 Terabit/s of combined capacity. However, these submarine cable infrastructures are concentrated about a single city i.e. Lagos leaving out the hinterlands and other major cities. Access to other parts of the country is choked due to the limitations of distribution infrastructure to the rest of the country. Owing to the foregoing, the market structure is skewed towards licensing and regulation of the radio spectrum space rather than by unbundling of the local loop. VSAT is still predominant medium for access to broadband Internet access especially in rural areas where use of mobile broadband is not practicable. It is estimated that $40 \%$ of Internet users are connected by VSAT, 39\% by broadband wireless, $4.9 \%$ by DSL, $4.3 \%$ via dial-up. Wi-Fi and leased lines are also used for internet connections.

The broadband market took a different outlook with the advent of MainOne cable in 2010 after it secured the broadband infrastructure licence for Lagos. Later in 2016, IHS Nigeria Limited secured a broadband infrastructure license for the North-Central region. Other regions such as the South-East, North-East, North-West, other parts of South west, South-South (which includes Edo State) are yet to have licensed Broadband infrastructure services provider. However, the creation of open access and shared infrastructure has boosted internet access across the country. NTEL operates the Sat-3/WASC and is gradually upgrading its national transmission capacity. Globacom launched its "Glo Xpress" long-distance transmission service in July 2005, and private operators have continued to invest heavily in the roll-out of their own microwave and wireless networks. Bitflux Consortium was licensed to offer wholesale wireless access services through the $2.3 \mathrm{GHz}$ spectrum across Nigeria. This will enable the company provide wholesale wireless broadband services and deepen broadband devices in line with the country's plan to achieve 30 per cent penetration by the end of 2018 .

In 2016 the roll out of $3 \mathrm{G}$ and $4 \mathrm{G}$ networks commenced with the launch of LTE-Advanced network by NTEL, which heralded the high speed internet experience. Prior to the advent of the LTE, there have been other ISPs that offered other variants of the $4 \mathrm{G}$ services. Such ISPs include Smile, Spectranet, Swift Networks, e-Stream, Cyberspace Networks, Hyperia, etc. Hyperia launched two new wireless broadband services: a new WiMAX service employing the $3.5 \mathrm{GHZ}$ spectrum, in Port Harcourt and a two-way broadband VSAT service in 2015. Its VSAT network uses both $\mathrm{C}$ band and $\mathrm{Ku}$ band, with its hub at its network operations center in London. The mobile network operators (MTN, 9mobile, Globacom, and Airtel) are not left out as each has currently demonstrated their capacity in rolling out the 4G-grade service. Notwithstanding the seemingly prevalent $4 \mathrm{G}$ revolution ongoing in Nigeria, it is not in dispute that all the $4 \mathrm{G}$ base stations are not linked to fibre backbone owing to the 
continued localization of the submarine cables in Lagos.

The National Broadband plan had in 2013 proposed and expected that by the end of 2017 it would have achieved a $3 \mathrm{G} / \mathrm{LTE}$ penetration rate of at least $70 \%$. However, it could be noted that this expectation is currently unrealistic owing to the prevailing uneven distribution infrastructure. Currently, only three (3) cities could be said to enjoy $4 \mathrm{G}$ services i.e. Lagos, PortHarcourt, and Abuja.

Broadband operators in Nigeria may be classified as: National carriers, National Mobile Operators, and Fixedwireless internet access providers.

The National Carriers are the mainstream bulk broadband operators. Currently there are three national carriers all of which are fixed-line operators namely: NTEL, Globacom, and MainOne. The national mobile operators include MTN, 9Mobile, Airtel. These operators have their own fiber-optic network infrastructure though not evenly distributed across all locations in Nigeria. The fixed wireless internet access providers are more in number but located mostly in the cities with their services not felt in the remote rural and semi-urban areas where many educational institutions are often located.

\section{Public Broadband Projects in Nigeria}

\subsection{The Rural Broad Band Initiative (RUBI)}

The RUBI project is the brainchild of the Universal Services Provision Fund (USPF) through which the Federal Government of Nigeria provides subsidies to operators for the deployment of network to support the establishment of core delivery mechanisms for broadband services in the rural/semi-urban areas of Nigeria. This project is in its pilot phase and has provided both wired and wireless internet at high speed in the rural areas at wholesale, and at the same time serving as catalyst for the uptake of other broadbanddependent projects in those locations such as e-library, ehealth, e-government, etc.[19]. Its objective is to deliver broadband services in the rural/semi-urban underserved and unserved areas. The funding is a one-off grant determined and awarded through a competitive bidding process. The selected companies build and operate the facilities to provide services to the communities.

Currently, Edo State is not yet listed as beneficiary States though there is likelihood that it would be part of the programme in the near future.

\subsection{The University InterCampus Connectivity (UnICC)}

This is a support project funded by the National Universities Commissions' Nigerian Research and Education Network (NgREN) project, the primary purpose of which is to deliver broadband infrastructure and access to facilitate research and learning using state of the art technology [20]. According to the USPF, "The UnICC Project is designed to seamlessly connect the networks of the main campuses of selected universities to the networks of their corresponding medical colleges and teaching hospitals through the deployment of fibre optic cable and its associated equipment". That is, the project is only aimed at providing connectivity between the various medical colleges of Universities in Nigeria. The project has two arms: Fibre interconnectivity between Universities and their corresponding Colleges of Medicine/Teaching Hospitals; and Electronic last mile user-devices (video conferencing system, CCTV system, smart classroom, data centres and IP telephone systems installed at the institutions). The objectives of the project are stated as follows:

a. Facilitate seamless connection between the Universities and their Medical Colleges to achieve bi-directional communication for the purpose of sharing and accessing information.

b. Provide a platform for sharing bandwidth resources and creating a reverse path for backup in the event of downtime.

c. Provide the requisite link for voice, data, video and other multimedia services (including conference facilities).

In Edo State, the only beneficiary of this project currently is the University of Benin Teaching Hospital located at Benin-Lagos road, Ugbowo, Benin city.

\subsection{BTRAIN - Backbone Transmission Infrastructure}

The Backbone Transmission Network (BTRAIN) Project is designed to facilitate the connection of the rural and semi urban areas to the National Transmission Backbone Infrastructure via fiber infrastructure [21]. The objective is to extend broadband to the underserved/unserved areas through Public-Private-Partnership (PPP) model. The identified advantages of this project are stated as follows:

The deployment of fibre optic cable in the target areas enhances network performance and quality of service.

a. Acceleration of service coverage in commercially unviable areas.

b. Increased/improved access to Internet in the target areas

c. Employment creation

d. Increased productivity

e. Enhanced ICT skills among beneficiaries

f. Beneficiaries are mainstreamed into global competitiveness

g. Accelerated socio-economic development

Currently, this project is only operational at four northern zones of Suleja-Izom, Apo-Keffi, Kano-Dutse, Minna-Bida. No southern state including Edo State is affected by this project.

\section{Network Design}

\subsection{Challenges of Affordable Broadband Internet in Educational Institutions}

Edo State is predominantly a state known for its home to many educational institutions especially tertiary institutions. Notable institutions including public and private are: Ambrose Alli University Ekpoma, Edo University Iyamho, 
University of Benin, Benson Idahosa university Benin, Samuel Adegboyega University Ogwa, Wellspring University, Igbinedion University Okada, Tayo Akapata University of Education Ekiadolor, Federal Polytechnic Auchi, Lighthouse Polytechnic Evbuonosa, Edo State Polytechnic Usen, Shaka Polytechnic Benin city, Edo State College of Agriculture Iguoriakh, etc. These are all centres of learning, research and skill acquisition. Reliable and affordable broadband internet is sine qua non to improving learning and research hence cannot be overemphasized. However, a review of Broadband internet across these institutions shows reveals that there is no affordable and reliable connections across the public institutions whereas the private institutions are seen to deploy a mixture of satellite and microwave connections with Smile and swift networks being the most commonly ISPs. However, these ISPs do not provide dedicated internet bandwidth.

\subsection{Proposed Solution}

The proposed network design is based on WiMAX technologies. The major Network components are: 170ft tower and WiMAX radios. A typical Wimax implementation can span 3000 square miles. A close examination of the institutions will reveal a sort of clustering in the sense that the relative distance of one institution from Benin where the Edo State Information Communications Agency is not up to 3000 kilometers. The height of the tower is important considering the geography of Edo state as well as the relative distances between the central coordinating center (perhaps the Edo State Information Communications agency) and the various institutions to which controlled access is to be given. The WiMAX radios are of two types: access and distribution radios. The access radio is used to receive bulk dedicated broadband bandwidth from the mainstream carriers such Glo, Airtel, NTEL etc. at an affordable rate. The distribution radio communicates to the subscribers which are educational institutions. The design is a point to multi-point design capable of supporting at least 50 clients. Figure 6 shows the relative distances of those institutions located outside Benin City (the reference location). The longest distance is $139 \mathrm{~km}$ which is the distance between Federal Polytechnic Auchi and Benin City. With these relative distances, it is appropriate to establish a single point of connectivity using WiMAX technology.

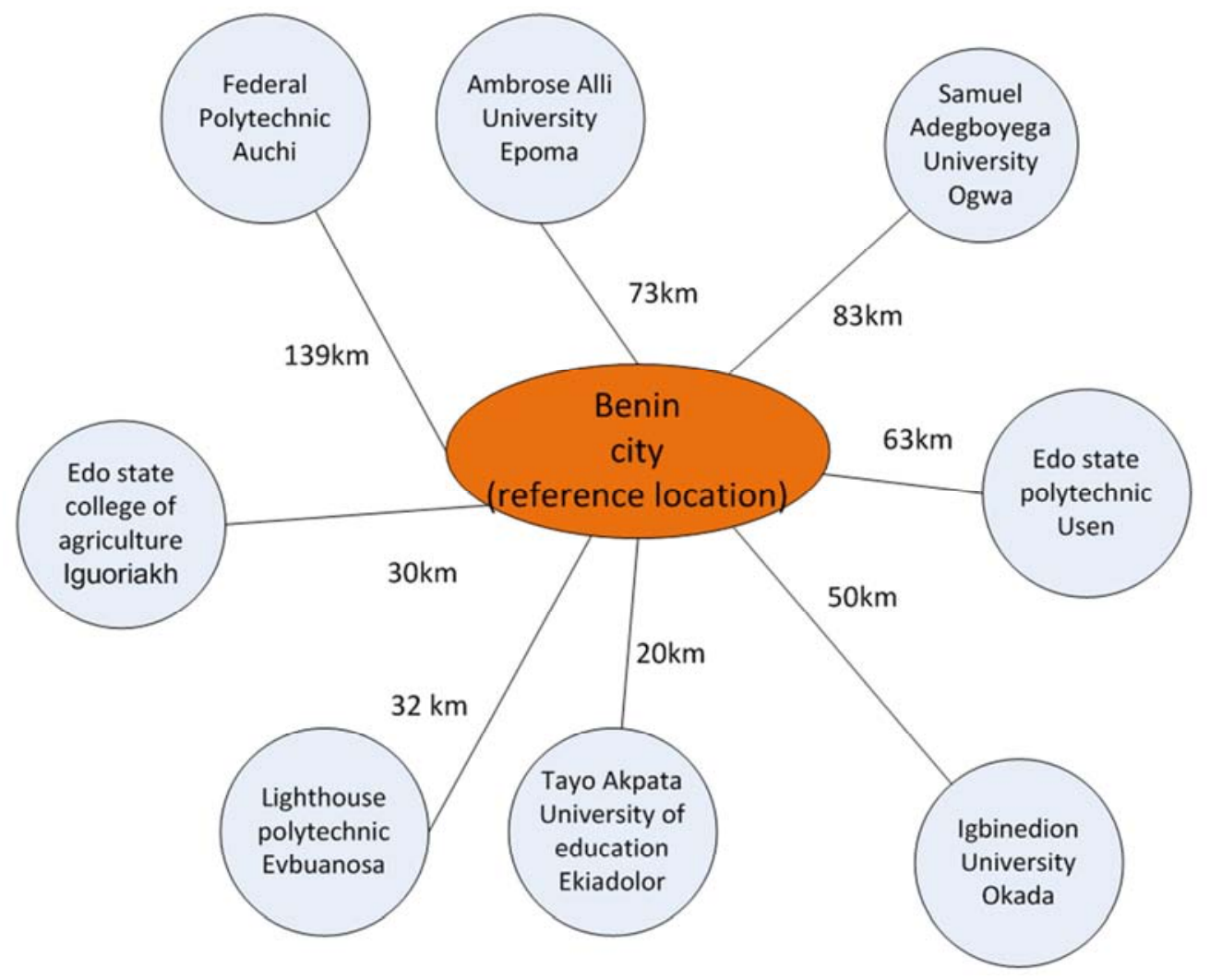

Figure 6. Relative line of sight distances of tertiary institutions in Edo State from Benin City.

\subsection{Implementation}

Implementation of a point-to-point is usually straightforward. The project implementation team should harness individual expertise and resources available to procure, install and commission the project.

The design in Figure 7 is a wireless leased broadband solution from a fixed wireless provider such as Glo, Airtel, NTEL, etc. using the WiMaX technology. The design is a point-to-point connection using powerful licensed full-duplex microwave radio such as Cablefree full outdoor microwave radio which can effectively connect multiple locations over $100 \mathrm{~km}$ apart with a throughput of about $3.5 \mathrm{Gbps}$ [22]. Lineof-sight transmissions are preferred as higher frequencies of 
up to $66 \mathrm{GHz}$ could be used which will ensure less interference and more bandwidth.

Prior to installation, a proper site survey should be conducted and necessary adjustments made and documented. Technologies available and providers should be reviewed to get the best solution available. It is expected that this phase would not pose a serious challenge to Edo State Government owing to the existence of a structured agency dedicated to ICT-related projects. Furthermore, the implementation may be done with inputs and agreements from all the management of the tertiary institutions in such a way that agreement as to pricing and likely bandwidth requirements of each institution are defined ab initio.

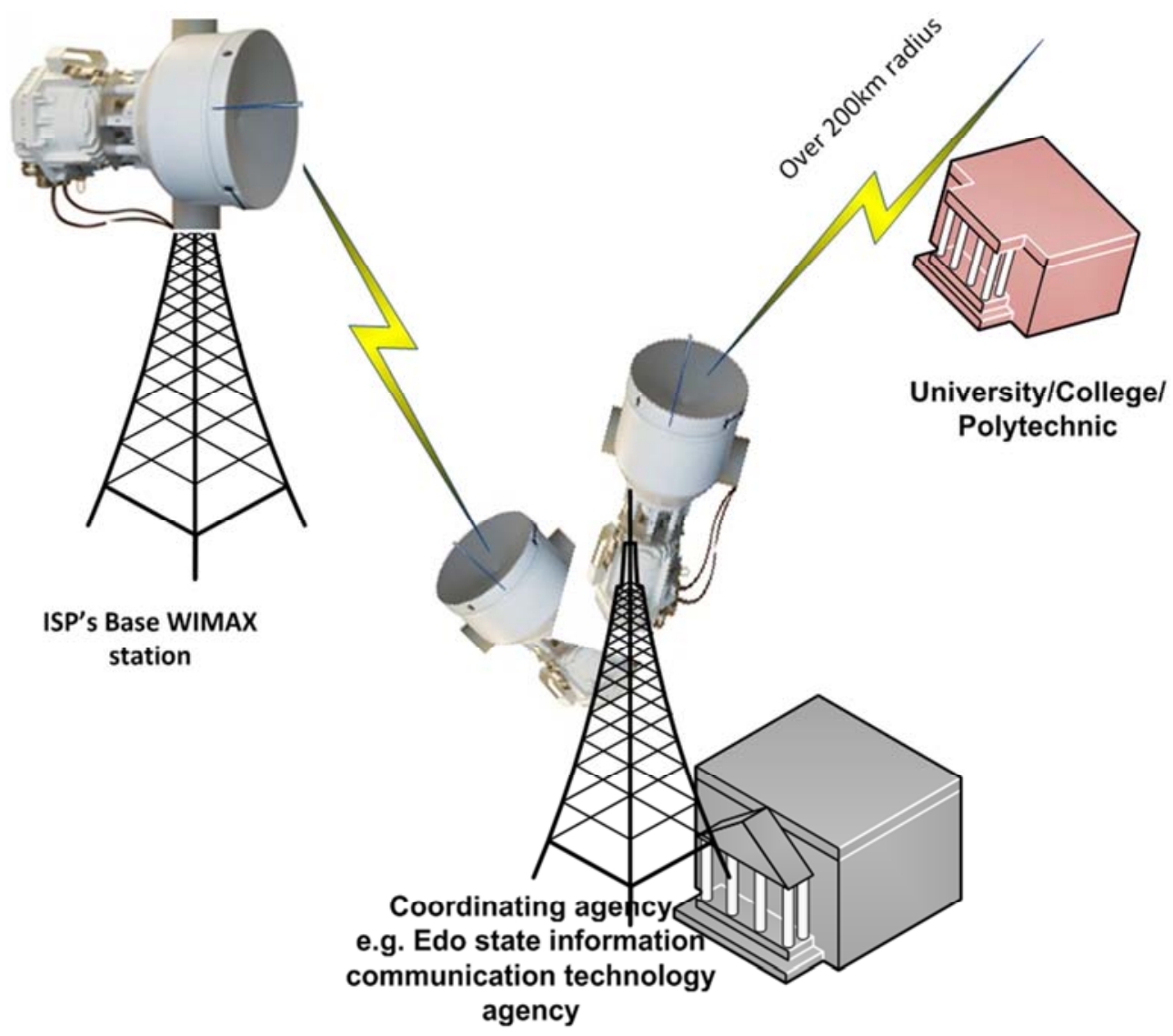

Figure 7. Implementation of a Microwave-based point-to-point leased solution.

\section{Conclusion}

This paper presents a concise framework for establishing reliable and high speed connections across tertiary Institutions in Edo state. It may be recalled that ITU in its state of broadband report has advised as follows: "Policymakers may wish to consider open access approaches to infrastructure, including infrastructure-sharing. Examples of open access arrangements include Local Loop Unbundling (LLU), wholesale broadband access, ducts and submarine cables. Previous ITU research suggests that growth in services has happened most rapidly where regulatory enablers (e.g. industry consultations, infrastructure-sharing) have been put in place to leverage the latest innovations. Although various strategies for open access exist, it is vital that policy-makers ensure that access to new facilities is provided on fair, reasonable and equivalent terms. This can also include the implementation of 'Dig Once' policies"[23]. It therefore follows that policy-makers such as the government agencies have a fundamental role in ensuring that policies regarding broadband internet access are realistic and not bogus documents meant for the shelves. Policy making is one thing and implementation is another. Like the National Broadband plan drafted in 2013 which has hardly had $30 \%$ of its provisions implemented, State government agencies such as the Edo State Information Communications Technology Agency should devise a plan or connectivity programme across the state to connect all educational and research-based institutions in such a controlled and affordable manner in line with the provisions of this paper.

\section{References}

[1] Ogunfuwa, I., "Despite massive investment, broadband plan totters"[online], 2017. Available at:

https://punchng.com/despite-massive-investment-broadbandplan-totters/.

[2] ITU, The State Of Broadband 2017: Broadband Catalyzing Sustainable Development, International Telecommunications Union, 2017. 
[3] Kim, Y., Kelly, T., and Raja, S., Building broadband: Strategies and policies for the developing world., 2010.

[4] Walke, B., The Roots of GPRS: The First System for Mobile Packet-Based Global Internet Access“, IEEE Wireless Communications, Oct. 2013, 12-23.

[5] WiMAX forum, Network Working Group Stage 2 Specification, Release 1.1, 2007.

[6] IEEE, IEEE 802.16: Wireless MAN Standard for Wireless Metropolitan Area Networks, 2009.

[7] Nedevschi, S., Surana, S., Du, B., Patra, R., Brewer, E., and Stan, V., Potential of CDMA450 for Rural Network Connectivity. IEEE Communications Magazine. Special Issue on New Directions In Networking Technologies In Emerging Economies, 2007.

[8] Federal Ministry of Communications Technology, National Broadband Plan, FMC, Abuja, 2013-2018.

[9] NTEL (2017), "About ntel" [online], 2017. Available at: http://www.ntel.com.ng/about-ntel/.

[10] Main One, "Submarine cable system", 2018, Available at: https://www.mainone.net/our-network/cable-system/.

[11] Brain \& Grabianowski, Next Generation Broadband in the Highlands and Islands of Scotland, 2013.

[12] Broadkin, J., "Satellite Internet faster than advertised, but latency still awful"[online], 2013. Available at: https://arstechnica.com/informationtechnology/2013/02/satellite-internet-faster-than-advertisedbut-latency-still-awful/\#p3n.

[13] Singleton, M., "The FCC has changed the definition of broadband"[online], 2015. Available at: https://www.theverge.com/2015/1/29/7932653/fcc-changeddefinition-broadband-25mbps.

[14] Thinkbroadband, "Satellite Broadband Guide"[online], 2018. Available at: https://www.thinkbroadband.com/guides/satellite-broadbandguide.
[15] Ofcom, "The availability of communications services in the UK"[online], 2013. Available at: https://www.ofcom.org.uk/research-and-data/multi-sectorresearch/availability-of-communication-services/economicgeography.

[16] Ground Control Global satellite communications, "Global Xpress - GX Inmarsat Services"[online], 2018. Available at: http://www.groundcontrol.com/Global_Xpress.htm.

[17] Petranovich, J., Mitigating the effects of weather on Ka-band high capacity satellites [online image], 2012. Available at: www.viasat.com/files/assets/.

[18] Kurbalija, J., AN INTRODUCTION TO INTERNET GOVERNANCE (4th edition), Diplo Foundation, Switzerland, 2010.

[19] USPF,"RUBI - Rural Broadband Initiative"[online], 2015. Available at: http://www.uspf.gov.ng/index.php?option=com_content\&view $=$ article\&id=11:rubi-rural-broadbandinitiative \& catid $=13 \&$ Itemid $=129$.

[20] USPF, "UnICC - University Inter Campus Connectivity" [online], 2015. Available at: $\mathrm{http}$ //www.uspf.gov.ng/index.php?option=com content\&view $=$ article\&id $=10$ :unicc-university-intercampusconnectivity\&catid=13\&Itemid $=129$.

[21] USPF, "BTRAIN - Backbone Transmission Infrastructure"[online], 2015. Available at: http://www.uspf.gov.ng/index.php?option=com_content\&view $=$ article $\&$ id $=8:$ btrain $\&$ catid $=13 \&$ Itemid $=129$.

[22] Cablefree,"Products" [online], 2017. Available at: http://www.cablefree.net/products/.

[23] ITU, "State of Broadband 2017 report issues 5 key recommendations to spur development"[online], 2018. Available at: http://news.itu.int/broadband-sustainabledevelopment/. 